\title{
Primary small-cell neuroendocrine carcinoma of the urinary bladder: A rare case and a review of the literature
}

\author{
ZUWEI LI ${ }^{1,2^{*}}$, CANBIN LIN $^{1,2^{*}}$, DANYUN WANG $^{3}$, JIANSEN XIE $^{2}$, CANKUN ZHOU $^{2}$, PEIJIE CHEN $^{1,2}$, \\ YU YANG ${ }^{1}$, SHUOLEI SUN ${ }^{1}$, JIAN PENG ${ }^{1}$, SHANGQI YANG ${ }^{1}$ and YONGQING LAI ${ }^{1}$ \\ ${ }^{1}$ Department of Urology, Peking University Shenzhen Hospital, Shenzhen, Guangdong 518036; ${ }^{2}$ Department of Urology, \\ Shantou University Medical College, Shantou, Guangdong 515041; ${ }^{3}$ Department of Anesthesiology, \\ Peking University Shenzhen Hospital, Shenzhen, Guangdong 518036, P.R. China
}

Received June 8, 2018; Accepted July 16, 2018

DOI: $10.3892 / \mathrm{mco} .2018 .1679$

\begin{abstract}
Primary small-cell neuroendocrine carcinoma (SCNEC) of the urinary bladder is a rare tumor characterized by poor differentiation and high aggressiveness. Only $\sim 150$ cases have been reported in the literature to date. We herein present a case of an 87-year-old man who presented with hematuria and was found to have an ill-defined mass in the urinary bladder on computed tomography and cystoscopic examination. On pathological examination following tumor biopsy, the mucosa of the bladder wall was found to be extensively infiltrated by neuroendocrine carcinoma, positive for CD56 and synaptophysin and negative for epithelial membrane antigen, consistent with SCNEC of the urinary bladder. The patient refused further surgical treatment and succumbed to the disease 2 months after the diagnosis. In the present study, this rare case of primary SCNEC of the urinary bladder is presented, along with a discussion on the clinical presentation, immunohistochemical and cytomorphological characteristics, management, biological behavior and prognosis of this disease.
\end{abstract}

\section{Introduction}

Bladder carcinoma is the fourth (7\%) most frequently newly diagnosed malignancy in men in USA, with an estimated incidence of 60,490 new cases and 12,240 deaths in 2017 (1). In recent decades, the incidence of bladder cancer in China has been increasing rapidly according to the 2014 Chinese Diagnosis and Treatment of Urological Diseases Guide. Neuroendocrine carcinoma, which includes carcinoid

Correspondence to: Professor Yongqing Lai, Department of Urology, Peking University Shenzhen Hospital, 1120 Lianhua Road, Shenzhen, Guangdong 518036, P.R. China

E-mail: yqlord@163.com

*Contributed equally

Key words: small-cell neuroendocrine carcinoma, bladder cancer, review tumors, large-cell neuroendocrine carcinomas and small-cell carcinomas, commonly occurs in the respiratory and gastrointestinal systems $(2,3)$. Primary small-cell neuroendocrine carcinoma (SCNEC) of the bladder is rare, accounting for $<1 \%$ of all bladder carcinomas $(4,5)$. To the best of our knowledge, only $\sim 150$ cases of primary SCNEC of the urinary bladder have been reported to date $(2,5)$. SCNEC of the urinary bladder is characterized by poor differentiation and high aggressiveness, and is frequently at an advanced stage when initially diagnosed, resulting in high metastatic potential and poor prognosis. The mean survival is only a few months and the mean 5-year survival rate is $\sim 8 \%(2,6)$. We herein report a case of primary SCNEC arising within the urinary bladder, along with a review of the relevant literature and a discussion of the clinical presentation, pathological characteristics, behavior, management and outcome of this disease. The study was approved by the Ethics Committee of Peking University Shenzhen Hospital (Shenzhen, China) and written informed consent was obtained from the patient for publication of the case details.

\section{Case report}

An 87-year-old male patient presented with gross hematuria for 15 days and was admitted to the local hospital. The patient had a smoking history of 40 pack-years, Ultrasonography revealed a $35 \times 31-\mathrm{mm}$ mass in the urinary bladder. The patient was diagnosed with bladder cancer and referred to the Peking University Shenzhen Hospital (Shenzhen, China) for further treatment. Laboratory tests were performed and the results were as follows: White blood cell (WBC) count, $11.59 \times 10^{9} / 1$ (normal range, 3.5-9.5x10 $/ 1$ ); neutrophilic granulocytes, $75.7 \%$ (normal range, 40-75\%); hemoglobin level, $128 \mathrm{~g} / 1$ (normal range, 130-175 g/l); urine sediment analysis: Red blood cell count, 1,061.9/ $\mu \mathrm{l}$ (normal range, 0-13.1/ $\mu \mathrm{l}$ ), WBC 1,151.2/ $\mu \mathrm{l}$ (normal range, $0-9.2 / \mu 1$ ). Plasma electrolytes, liver and kidney function tests were within the normal range. The computed tomography (CT) scans revealed a 51x31-mm ill-defined mass involving the right wall of the urinary bladder and the CT number was $47 \mathrm{HU}$ (Fig. 1A). In addition, heterogeneous enhancement was observed in the arterial phase (CT number: $60 \mathrm{HU}$; Fig. 1B). Of note, the right bladder wall was thickened locally, and it was considered likely that the bladder cancer 
A

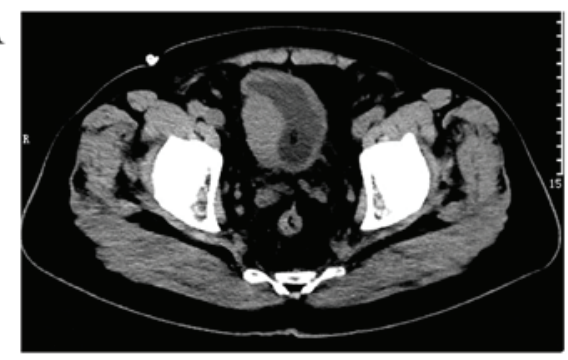

$\mathrm{C}$

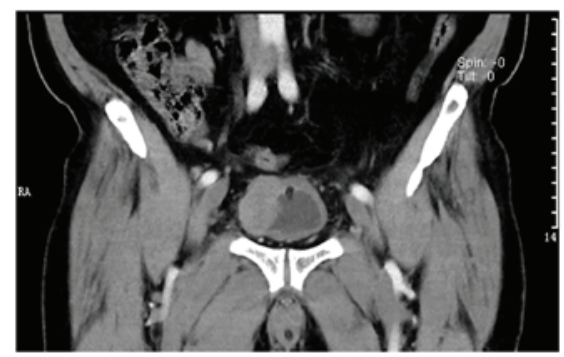

$\mathrm{B}$

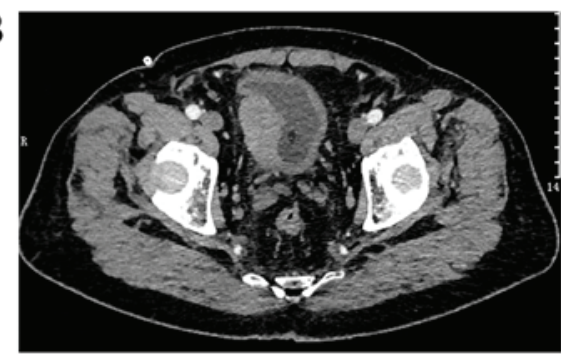

$\mathrm{D}$

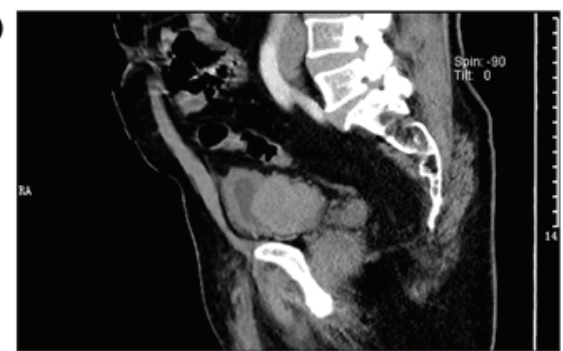

Figure 1. (A) Computed tomography (CT) scans demonstrated a 51x31-mm ill-defined mass involving the right wall of the urinary bladder; the CT number was 47 HU. (B) Heterogeneous enhancement was observed in the arterial phase; the CT number was 60 HU. (C) Coronal plane. (D) Sagittal plane.

invaded the outer wall. Images at the coronal and sagittal planes are shown in Fig. 1C and D, respectively. Cystoscopic examination revealed a $4 \times 3-\mathrm{cm}$ sessile tumor mass in the right wall of the urinary bladder. Some of tumor tissues were clamped and removed for a biopsy. As shown in Fig. 2, pathological examination with hematoxylin and eosin staining demonstrated that the mucosa of the bladder wall was extensively infiltrated by neuroendocrine carcinoma, consistent with SCNEC. The results of immunohistochemistry revealed that the tumor cells were $\mathrm{CD}_{56}{ }^{+}$, synaptophysin (Syn) ${ }^{+}$and epithelial membrane antigen-. The patient refused further surgical treatment after being informed on the associated morbidity risk, and eventually succumbed to the disease 2 months after the diagnosis.

\section{Discussion}

Primary SCNEC of the urinary bladder, first reported by Cramer in 1981 (7), is a rare aggressive malignant neoplasm with a high incidence of local recurrence and metastasis $(8,9)$. This malignancy commonly affects male patients aged $50-80$ years $(10,11)$, although it may be observed in patients aged 35-87 years based on the current literature (12). SCNECs of the urinary bladder may be associated with longstanding cystitis, bladder lithiasis and smoking $(6,13)$, as was the case in our patient. Of note, this type of cancer more often involves the right lateral wall of the urinary bladder. The most common clinical presentation is hematuria, which may be accompanied by pain, dysuria, hypertension and muscle weakness due to hypokalemia (11,14-16). The differential diagnosis includes small-cell carcinoma of the urinary bladder, high-grade urothelial carcinoma (lymphoma-like variant), lymphoma, non-Hodgkin lymphoma, and metastatic malignant round-cell neoplasms, particularly from pulmonary tissue.

There is no consensus regarding the origin and histogenesis of SCNEC of the urinary bladder. Some researchers hypothesized an origin from totipotent stem cells in the submucosa of the urinary bladder. Metaplastic differentiation from transitional cell carcinoma has also been suggested.

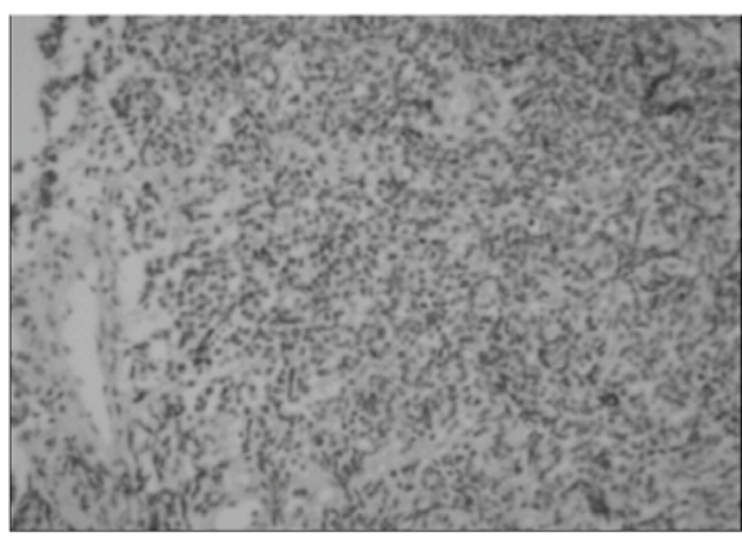

Figure 2. Pathological examination demonstrated that the mucosa of the bladder wall was heavily infiltrated by neuroendocrine carcinoma, consistent with primary small-cell neuroendocrine carcinoma (hematoxylin and eosin staining; magnification, x200).

Both hypotheses may account for the coexistence of other histological types of tumors occasionally seen in primary SCNECs of the urinary bladder $(11,17,18)$, while malignant transformation of neuroendocrine cells is considered to be closely associated with tumorigenesis $(17,19)$. The cytomorphological characteristics of primary SCNEC of the bladder are indistinguishable from metastatic SCNEC. Ali et al conducted a clinicopathological study with 23 patients, and reported that isolated single cells with near-naked nuclei and scant cytoplasm were always detected; hypercellularity and anisonucleosis were present in $90 \%$ of the cases; other cytomorphological characteristics included nuclear molding (75\%), hyperchromatic nuclei $(75 \%)$, high mitotic karyorrhectic index (45\%) and inflammatory background (40\%) (17). Diagnosis of primary SCNEC of the bladder mainly depends on histopathology, immunohistochemistry and cytomorphological characteristics, which is similar to SCNEC in the lung and other tissues. An analysis of clinicopathological 
characteristics revealed that 12 cases of SCNEC of the bladder expressed CD56 (12/12), Syn (11/12), chromogranin A (CgA; 8/12) and thyroid transcription factor-1 (9/12) (20). Chen et al also verified that CD56, Syn, neuron-specific enolase and $\mathrm{CgA}$ are positive and sensitive markers for small-cell carcinoma of the bladder (21), which was consistent with the immunohistochemical findings in the present case. There is no general consensus or guideline for the management of this malignancy. A multimodal approach is recommended by the Canadian Association of Genitourinary Medical Oncologists $(22,23)$. Transurethral resection of bladder tumor and radical cystectomy are considered as surgical treatment options based on each individual patient (23). Adjuvant chemotherapy has been well-documented to increase long-term survival rates.

Siefker-Radtke et al have confirmed that the 5-year survival of patients treated with radical cystectomy after preoperative chemotherapy increased by $42 \%$ compared with patients treated with radical cystectomy alone (24). Radiation therapy is also recommended for SCNEC of the bladder with skull or bone metastasis (21).

The number of reports on the biological behavior and prognosis of SCNEC of the bladder to date is insufficient. Chen et al reported that the 1-, 2-, 3- and 4-year survival rates were $57.78,36.94,16.61$ and $2.97 \%$, respectively, with a mean survival time of 20.54 months (21). Choong et al reported that the 5-year survival rate of small-cell carcinoma of the bladder was $25 \%$ (4). Zhou et al demonstrated that overall survival was associated with factors such as patient age, size and shape of the tumor, perineuronal invasion, vascular invasion, distant organ metastasis and pathological type (20).

In conclusion, SCNEC of the urinary bladder is a rare aggressive malignant neoplasm with a high incidence of local recurrence and metastasis. The diagnosis of this malignancy mainly depends on histopathology, immunohistochemistry and cytomorphological characteristics. Multimodal approach to treatment is recommended, although the prognosis is poor. Long-term follow-up is warranted due to the risk of local recurrence and distant metastasis.

\section{Acknowledgements}

Not applicable.

\section{Funding}

This study was supported by Science and Technology Development Fund Project of Shenzhen (grant no. JCYJ20170307111334308), Clinical Research Project of Shenzhen Health Commission (grant no. SZLY2018023) and the Fund of 'San-ming' Project of Medicine in Shenzhen (grant no. SZSM201612066).

\section{Availability of data and materials}

Not applicable.

\section{Authors' contributions}

ZL and CL performed data collection and data interpretation as well as drafting the manuscript. DW, CZ and JX contributed to the study design and acquisition of data. PC, YY, SS, JP and SY participated in the study design, data collection, data analysis and follow-up analysis of the patient. YL contributed to study design, as well as the analysis and interpretation of data. All the authors have read and approved the final version of this manuscript.

\section{Ethics approval and consent for publication}

The study was approved by the Ethics Committee of Peking University Shenzhen Hospital (Shenzhen, China).

\section{Patient consent for publication}

Written informed consent was obtained from the patient for the publication of the case details.

\section{Competing interests}

The authors declare that they have no competing interests.

\section{References}

1. Siegel RL, Miller KD and Jemal A: Cancer Statistics, 2017: CA Cancer J Clin 67: 7-30, 2017.

2. Hussein MR, Al-Assiri M, Eid RA and Musalam AO: Primary small cell neuroendocrine carcinoma of the urinary bladder: A clinicopathologic, immunohistochemical and ultrastructural evaluation. Ultrastruct Pathol 34: 232-235, 2010.

3. Zakaria A, Al Share B, Kollepara S and Vakhariya C: External beam radiation and brachytherapy for prostate cancer: Is it a possible trigger of large cell neuroendocrine carcinoma of the urinary bladder? Case Rep Oncol Med 2017: 1853985, 2017.

4. Choong NW, Quevedo JF and Kaur JS: Small cell carcinoma of the urinary bladder. The mayo clinic experience. Cancer 103: 1172-1178, 2005.

5. Wang X, Zhang S, MacLennan GT, Eble JN, Lopez-Beltran A, Yang XJ, Pan CX, Zhou H, Montironi R and Cheng L: Epidermal growth factor receptor protein expression and gene amplification in small cell carcinoma of the urinary bladder. Clin Cancer Res 13: 953-957, 2007.

6. Ahsaini M, Riyach O, Tazi MF, El Fassi MJ, Farih MH, Elfatmi $\mathrm{H}$ and Amarti A: Small cell neuroendocrine carcinoma of the urinary tract successfully managed with neoadjuvant chemotherapy. Case Rep Urol 2013: 598325, 2013.

7. Cramer SF, Aikawa M and Cebelin M: Neurosecretory granules in small cell invasive carcinoma of the urinary bladder. Cancer 47: 724-730, 1981.

8. McClellan T, DeBord J, Franklin G and Tierney J: Small cell neuroendocrine carcinoma of the urinary bladder: Case report of a rare primary tumor. W V Med J 97: 151-152, 2001.

9. Kickuth R, Laufer U, Pannek J, Adamietz IA, Liermann D and Adams S: Magnetic resonance imaging of bone marrow metastasis with fluid-fluid levels from small cell neuroendocrine carcinoma of the urinary bladder. Magn Reson Imaging 20: 691-694, 2002.

10. Holmang S, Borghede G and Johansson SL: Primary small cell carcinoma of the bladder: A report of 25 cases. J Urol 153: 1820-1822, 1995 .

11. Lau SK and Zhang Y: Pathologic quiz case. A 73-year-old man with a bladder mass. Combined primary small cell neuroendocrine carcinoma and high-grade papillary urothelial carcinoma of the urinary bladder. Arch Pathol Lab Me 128: 1055-1056, 2004.

12. Nabi G, Singh I, Ansari MS, Sharma MC and Dogra PN: Primary small cell neuroendocrine carcinoma of urinary bladder: An uncommon entity to be recognized. Int Urol Nephrol 33: 637-640, 2001.

13. Alijo Serrano F, Sanchez-Mora N, Angel Arranz J, Hernandez C and Alvarez-Fernandez E: Large cell and small cell neuroendocrine bladder carcinoma: Immunohistochemical and outcome study in a single institution. Am J Clin Pathol 128: 733-739, 2007. 
14. Blomjous CE, Vos W, De Voogt HJ, Van der Valk P and Meijer CJ: Small cell carcinoma of the urinary bladder. A clinicopathologic, morphometric, immunohistochemical and ultrastructural study of 18 cases. Cancer 64: 1347-1357, 1989.

15. Akamatsu S, Takenawa J, Kanamaru S and Soeda A: Ectopic adrenocorticotropic hormone syndrome in a case of small cell carcinoma of the bladder manifesting as severe muscle weakness. Urology 68: 1122.e5-e8, 2006.

16. Partanen S and Asikainen U: Oat cell carcinoma of the urinary bladder with ectopic adrenocorticotropic hormone production. Hum Pathol 16: 313-315, 1985

17. Ali SZ, Reuter VE and Zakowski MF: Small cell neuroendocrine carcinoma of the urinary bladder. A clinicopathologic study with emphasis on cytologic features. Cancer 79: 356-361, 1997.

18. Shahab N: Extrapulmonary small cell carcinoma of the bladder. Semin Oncol 34: 15-21, 2007.

19. Young RH and Parkhurst EC: Mucinous adenocarcinoma of bladder. Case associated with extensive intestinal metaplasia of urothelium in patient with nonfunctioning bladder for twelve years. Urology 24: 192-195, 1984

20. Zhou HH, Liu LY, Yu GH, Qu GM, Gong PY, Yu X and Yang P: Analysis of clinicopathological features and prognostic factors in 39 cases of bladder neuroendocrine carcinoma. Anticancer Res 37: 4529-4537, 2017.

21. Chen Z, Liu Q, Chen R, Liu Z, Li M, Ling Q, Wu L, Yang J, Liu X, Wang T, et al: Clinical analysis of small cell carcinoma of the bladder in Chinese: Nine case reports and literature reviews. World J Surg Oncol 15: 33, 2017.
22. Moretto P, Wood L, Emmenegger U, Blais N, Mukherjee SD, Winquist E, Belanger EC, Macrae R, Balogh A, Cagiannos I, et al: Management of small cell carcinoma of the bladder: Consensus guidelines from the Canadian Association of Genitourinary Medical Oncologists (CAGMO). Cana Urol Assoc J 7: E44-E56, 2013.

23. Celik O, Ekin G, Ipekci T, Budak S and Ilbey YO: Diagnosis and treatment in primary bladder small cell carcinoma: Literature review. Arch Ital Androl 88: 52-55, 2016.

24. Siefker-Radtke AO, Dinney CP, Abrahams NA, Moran C, Shen Y, Pisters LL, Grossman HB, Swanson DA and Millikan RE: Evidence supporting preoperative chemotherapy for small cell carcinoma of the bladder: A retrospective review of the M. D. Anderson cancer experience. J Urol 172: 481-484, 2004. 